\title{
A Mutation in Lamin A/C Gene Previously Known to Cause Emery- Driefuss Muscular Dystrophy Causing A Phenotype of Limb Girdle Muscular Dystrophy Type 1B
}

\author{
Albi J Chalissery ${ }^{1^{*}}$, Tudor Munteanu ${ }^{1}$, Yvonne Langan ${ }^{2}$, Francesca Brett ${ }^{2}$ and Janice Redmond ${ }^{1}$ \\ ${ }^{1}$ Department of Neurology, St James's Hospital, Ireland \\ ${ }^{2}$ Department of Neurophysiology, St James's Hospital, Ireland \\ ${ }^{3}$ Department of Neuropathology, Beaumont Hospital, Dublin, Ireland \\ *Corresponding author: Albi J Chalissery, Department of Neurology, St James's Hospital, James's Street, Dublin 8, Ireland, Tel +353 14103000 ; E-mail: \\ achalissery@stjames.ie
}

Rec date: Feb 19, 2016; Acc date: Apr 13, 2016; Pub date: Apr 18, 2016

Copyright: (c) 2016 Chalissery AJ, et al. This is an open-access article distributed under the terms of the Creative Commons Attribution License, which permits unrestricted use, distribution, and reproduction in any medium, provided the original author and source are credited.

\begin{abstract}
Mutations in the lamin protein(found in the nuclear envelope) known to cause different allelic disorders including limb girdle muscular dystrophies (LGMD) and Emery-Dreifuss muscular dystrophy (EDMD). LGMDs are a heterogeneous group of disorders with progressive proximal muscle weakness in an autosomal inheritance pattern. LGMD type $1 \mathrm{~B}$ is a disorder secondary to a mutation in the gene encoding Lamin $\mathrm{A} / \mathrm{C}$ protein in the nuclear envelope. We report a heterozygous mutation (c.148C $>$ T mutation) in the lamin A/C gene causing LGMD type 1B in a family. This mutation was previously reported to cause EDMD. Repeated muscle biopsies and using ever advancing molecular genetics assisted in establishing the diagnosis. Our case demonstrates the need for pursing investigations as cardiac involvement and sudden death is common in this group.
\end{abstract}

Keywords: Mutations; Lamin protein; Limb girdle muscular dystrophies; Distal muscle weakness

\section{Introduction}

Limb girdle muscular dystrophies are a group of disorders characterized by progressive proximal muscle weakness with autosomal patterns of inheritance. Since the advances in molecular genetics in the last decade, novel genes associated with LGMD have been discovered. The phenotype of LGMD typically includes predominant weakness in proximal limb muscles with sparing of the facial muscles. Distal muscle weakness may occur in severe cases or later in the disease course. Due to the heterogeneity and overlap with other diseases the diagnostic approach is often difficult in LGMD. LGMD type $1 \mathrm{~B}$ is caused by mutations in the lamin $\mathrm{A} / \mathrm{C}$ (LMNA) gene on chromosome 1q11-21[1]. Point mutations, deletions, duplications and insertion mutations have been reported in LMNA gene [2]. We present a patient with LGMD type $1 \mathrm{~B}$ with a novel heterozygous mutation in the lamin $\mathrm{A} / \mathrm{C}$ gene.

\section{Case Presentation}

A 47-year old woman presented with progressive proximal weakness of the extremities since early adulthood. She reported ongoing fatigue with cramps in the hands and feet. Difficulty walking was prominent. She had to walk backwards when coming down the stairs when not wearing shoes. Lifting objects from the top shelf became very difficult and she also noted reduced grip strength in her hands. Her past medical history included a euthyroid goitre, atrial fibrillation and failed cardioversion twice. Medications included warfarin and bisoprolol. There was a family history of proximal limb weakness in her father who died in his early forties due to heart disease and her son was noted to have frequent falls from six years of age. Examination revealed atrial fibrillation. There was proximal weakness in both upper and lower extremities. There was also mild weakness of ankle dorsiflexion and plantar flexion. Strength in the facial muscles was normal. Reflexes were reduced in the upper limbs and absent in lower limbs. There were no joint contractures.

Investigations included raised creatine kinase levels (range 200-1500 IU/L) and EMG showed features of myopathy. Magnetic resonance imaging (MRI) of the lower extremities showed quadriceps muscle atrophy. Muscle biopsy was inconclusive for both routine and specialized immunostaining for dystrophin, sarcoglycan, lamin A/C and desmin. Cardiac MRI showed dilatation and hypertrophy of the four chambers and with a dilated hypokinetic left ventricle. Over the next seven years her mobility deteriorated and she became wheelchair bound. Ambulatory holter monitoring showed asymptomatic pauses of up to 2.8 seconds and ventricular dysarrhythmias. A cardiac defibrillator was inserted. A repeat muscle biopsy from the right quadriceps was abnormal with variation in muscle fibre size, type 2 fibre atrophy and there was no evidence of inflammation (Figure 1). With extensive DNA analysis a heterozygous mutation in Lamin A/C gene (p.Arg50Cys) was discovered.

Our patient's son who is now 17 -years of age was recently reviewed in our service. He was born at term and had no difficulties in the neonatal period. He started to walk at the age of 14 months and noted to have intermittent falls while walking without any clear reason from the age of 3 years. He was subsequently noted to be toe walking and required achilles tendon and hamstrings lengthening procedures bilaterally at the age of 15 years. Examination showed a mild myopathic gait only. MRI of lower extremities was normal. The same mutation in lamin A/C gene was identified implying pathogenicity of this mutation in this family. No muscle biopsy was done. 


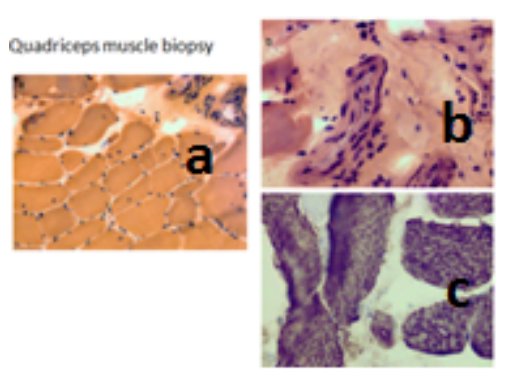

Figure 1: Muscle biopsy of the quadriceps (right) revealed variation in fibre size with haematoxylin and eosin stain (a); No evidence of inflammation with haematoxylin and eosin stain (b); type 2 fibre atrophy with myosin $\operatorname{stain}(\mathrm{c})$. Scale bar $=40 \mu \mathrm{m}$ in panel a and 60 $\mu \mathrm{m}$ in panels $\mathrm{b}$ and $\mathrm{c}$.

\section{Discussion}

The clinical spectrum of diseases caused by different lamin mutations (Laminopathies) constitute $5-10 \%$ of LGMDs and have different phenotypes. Lamin is a main component of nuclear protein and is a type $\mathrm{V}$ intermediate filament protein, the function of which is not completely understood. Lamin is expressed in a number of human tissues (muscle, bone, heart, adipose tissue and blood vessels). Some phenotypes involve multiple systems and some involve only skeletal muscles or skin. There are at least 8 allelic disorders identified [2]. These include LGMD type $1 \mathrm{~B}$, autosomal dominant dilated cardiomyopathy with conduction defects, autosomal dominant EmeryDreifuss Muscular dystrophy (AD EDMD), autosomal recessive Charcot-Marie-Tooth disease type 2, mandibuloacral dysplasia, familial partial lipodystrophy, Hutchinson-Gilford progeria, and atypical Werner syndrome.

The first lamin mutation was identified in autosomal dominant EDMD by work of Bonne $\mathrm{G}$ et al. [3]. The pattern of inheritance in EDMD can be $\mathrm{X}$ linked (the most common form), autosomal dominant and autosomal recessive. LGMD type $1 \mathrm{~B}$ and autosomal dominant EDMD are overlapping syndromes with varying degrees of muscle weakness, joint contractures and cardiac involvement. In EDMD, the earliest feature is joint contractures, associated with progressive involvement and wasting of humeropeoneal muscles and cardiac involvement (arrhythmias, conduction defects and cardiomyopathy). Cardiac defibrillator placement is needed by adulthood. Features of the autosomal dominant forms are variable and some involve cardiac muscles without major skeletal muscle involvement. Patients with LGMD type $1 \mathrm{~B}$ have an autosomal dominant inheritance pattern and typically present with slowly progressive pelvic and scapular girdle muscle weakness from the second decade (different topography compared to EDMD). Joint contractures and cardiac involvement occur similar to EDMD [4]. The joint contractures may be either absent or mild with late onset LGMD type 1B [5].

Atrioventricular conduction disturbances, dysrhythmias and dilated cardiomyopathy may occur, with risk of sudden death two-three decades later [4]. A family was previously reported with a novel mutation in LMNA (missense mutation c.80C $>\mathrm{T}$ in exon 1) gene causing LGMD1B and a SCN5A gene mutation causing brugada syndrome. Eight family members died before the diagnosis was made and they had early cardiac involvement [7]. Partial epilepsy [8] and cardioembolic stroke [9] were also recently reported in patients with LGMD1B. Diagnosis of LGMDs are challenging with varying clinical phenotypes and genetic abnormalities. The specificity is poor with neurophysiologic tests and other complementary tests such as creatine kinase. Various modalities of imaging are used to study the severity of muscle atrophy and changes in connective tissues. MRI has more advantages than using ultrasound and computed tomography. Due to optimal soft tissue characterization, MRI can reveal muscle oedema, differentiate the specific pattern of involvement of muscles in different muscular conditions and fat replacement of muscles. Imaging can also guide the site of biopsy and muscle biopsy remains the gold standard for diagnosis [10].

Our patient had a history of muscle problems in an autosomal dominant inheritance pattern and proximal muscle weakness began in early adulthood and progressively deteriorated over the next two decades. Cardiac involvement was evident from the third decade and needed defibrillator placement. Joint contractures were only seen in our patient's son. Initial muscle biopsy was nondiagnostic and extensive molecular analysis on the repeat muscle biopsy seven years later lead to the diagnosis. Direct fluorescent sequencing for exons112 of the LMNA gene showed a heterozygous state for $(c .148 \mathrm{C}>\mathrm{T}$ (p.Arg50Cys) mutation in exon 1 of the LMNA gene. C.148C $>$ T results in the substitution of a basic arginine residue with a neutral polar cysteine residue. This mutation has not been identified in LGMD type $1 \mathrm{~B}$ to the best of our knowledge but has been reported to the Leiden Muscular Dystrophy database as pathogenic in patients affected by Emery-Driefuss Muscular Dystrophy. The possibility of a benign polymorphism of c. $148 \mathrm{C}>\mathrm{T}$ cannot be ruled out but the identification of the same mutation in the affected son suggested pathogenicity of this heterozygous mutation in this family. Our case demonstrates the importance of pursuing molecular genetics in identifying the underlying diagnosis. Ongoing cardiac assessment is essential due to and risk of sudden death in this group of patients.

\section{References}

1. Van der Kooi AJ, van Meegen M, Ledderhof TM, McNally EM, de Visser $\mathrm{M}$, et al. (1997) Genetic localization of a newly recognized autosomal dominant limb-girdle muscular dystrophy with cardiac involvement (LGMD1B) to chromosome 1q11e21. Am J Hum Genet 60: 891-895.

2. Luo Y-B, Mastaglia FL, Wilton SD (2014) Normal and aberrant splicing of LMNA. J Med Genet 51: 215-223.

3. Bonne G, Di Barletta MR, Varnous S, Bécane HM, Hammouda EH, et al. (1999) Mutations in the gene encoding lamin A/C cause autosoma dominant Emery-Dreifuss muscular dystrophy. Nat Genet 21: 285-288.

4. $\mathrm{N}$ Vincenzo, $\mathrm{M}$ Savarese. Genetic basis of limb-girdle muscular dystrophies: the 2014 update. Acta Myol 33: 1-12

5. Rosales XQ, al-Dahhak R, Tsao CY (2012) Childhood Onset of LimbGirdle Muscular Dystrophy. Pediatr Neurol 46: 13-23.

6. Muchir A, Bonne G, van der Kooi AJ, van Meegen M, Baas F, et al. (2000) Identification of mutations in the gene encoding lamin $\mathrm{A} / \mathrm{C}$ in autosomal dominant limb girdle muscular dystrophy with atrioventricular conduction disturbances (LGMD1B). Hum Mol Genet 9: 1453-1459.

7. Nzwalo H, Conceicao I, Pereira P, Santos R, Evangelista T (2013) A family with 2 different hereditary diseases leading to early cardiac involvement. J Clin Neuromuscul Dis 14: 204-208

8. Tsao CY, Mendell JR (2009) Partial epilepsy in an adolescent male with limb girdle muscular dystrophy 1B. J Child Neurol 24: 346-348. 
Citation: Chalissery AJ, Munteanu T, Langan Y, Brett F, Redmond J (2016) A Mutation in Lamin A/C Gene Previously Known to Cause EmeryDriefuss Muscular Dystrophy Causing A Phenotype of Limb Girdle Muscular Dystrophy Type 1B. J Clin Case Rep 6: 770. doi: 10.4172/2165-7920.1000770

Page 3 of 3

9. Chen CH, Tang SC, Su YN, Yang CC, Jeng JS, et al. (2013) Cardioembolic stroke related to limb-girdle muscular dystrophy 1B. BMC Research Notes 6: 32 .
10. Ortolan P, Zanato R, Coran A, Beltrame V, Stramare R (2015) Role of radiologic imaging in genetic and acquired neuromuscular disorders. Eur J Transl Myol 25: 5014 